\title{
An Inventory Production Model for Deteriorating Items Allowing Price Discount with Permissible Delay in Payments
}

\author{
Janardan Behera ${ }^{1}$, Bidyadhara Bishi ${ }^{2}$, Sudhir Kumar Sahu ${ }^{3}$ \\ ${ }^{1}$ Research Scholar, P.G. Department of Statistics, Sambalpur University,Odisha-768019 \\ ${ }^{2}$ Researcher, P.G. Department of Statistics, Sambalpur University,Odisha-768019 \\ ${ }^{3}$ Professor in Management Sciences, Mahatma Gandhi, Central University, Motihari, Bihar-845401
}

\begin{tabular}{ll}
\hline ARTICLE INFO & ABSTRACT \\
\hline Published Online & The present Paper deals with an inventory production policy for a ramp type deteriorating item over \\
& a finite planning horizon with constant demand, finite production rate and shortages are not allowed. \\
& The optimal number of production cycles that minimizes the average system cost is determined. The \\
& model permits inventory shortage in each cycle, which is completely backlogged within the cycle \\
& itself. Every cycle starts with zero stock and production. As production continues, the inventory \\
& begins to accumulate after meeting current demands. The excess inventory accumulated during the \\
& production period is used to account for demand and deterioration in the no-production period.
\end{tabular}

Corresponding Author: Numerical examples, tables, and final concluding remarks are discussed in the subsequent sections.

Bidyadhara Bishi Numerical example solved by using Mathematica software.

KEYWORDS: Production, deterioration, permissible delay, price discount, shortages.

\section{INTRODUCTION}

In an inventory Production model determines the quantity of a product to be produced on a single facility that meets a deterministic demand. The main objective of any business is to maximize profit and to minimize the total cost, for which one should have knowledge of time of running the production and how much to be produced. The answers to these questions depend on a large number of factors, for example the nature of demand for different items, circumstances governing replenishment, various costs such as inventory setup cost, holding cost and deteriorating cost. Usually, the nature of all items deteriorates over a time frameHou and Lin (2009) developed a cash flow oriented EOQ model with deteriorating items under permissible delay in payments and the minimum total present value of the costs is obtained. In this paper all results have been obtained by taking constant net discount rate of inflation $\mathrm{k}$. He obtained minimum total present value of the costs over the time horizon. Aggrawal et al. (2009) developed a model on integrated inventory system with the effect of inflation and credit period. In this model the demand rate is assumed to be a function of inflation. This EOQ model is applicable when the inventory contains trade credit that supplier give to the retailer. Tripathi and Misra (2010) developed EOQ model credit financing in economic ordering policies of non- deteriorating items with time- dependent demand rate in the presence of trade credit using a discounted cash-flow (DCF) approach. Jaggi et al. (2008) developed a model retailer's optimal replenishment decisions with creditlinked demand under permissible delay in payments.

This paper incorporates the concepts of credit linked demand and developed a new inventory model under two levels of trade credit policy to reflect the real-life situation .Bishi, Behera, and Sahu(2018) presented the deteriorating inventory model with linear, exponential demand with shortage. Bishi, Behera, and Sahu(2018) presented the TwoWarehouse Inventory Model for Non-Instantaneous Deteriorating Items with Exponential Demand Rate and Shortages developed by Huang (2007) and obtained the retailer's optimal replenishment policy under permissible delay in payments. Jaggi et al. (2007) developed an inventory model under two levels of trade credit policy by assuming the demand is a function of credit period offered by the retailer to the customers using discounted cash-flow (DCF) approach. Optimal retailer's ordering policies in the EOQ model for deteriorating items under trade credit financing in supply chain was developed by Mahata and Mahata (2009). 


\section{“An Inventory Production Model for Deteriorating Items Allowing Price Discount with Permissible Delay in Payments"}

In this paper authors obtained a unique optimal cycle time to minimize the total variable cost per unit time. Davis and Gaither (1985) developed EOQ models for firms offering a one-time opportunity to delay payments by their supplier for the order of an item. Goyal (1985) developed an EOQ model under condition of permissible delay in payments. He ignored the difference between the selling price and the purchase cost, and concluded that the economic replenishment interval and order quantity generally increases marginally under the permissible delay in payments. Dave (1985) corrected Goyal's model by assuming the fact that the selling price is necessarily higher than its purchase cost. Other many related articles can be found by Aggarwal and Jaggi (1995), Jamal et al. (1997), Sarker et al. (2000), Ouyang et al. (2006). Ghare and Schrader (1963) developed EOQ model with constant deterioration rate. Various types of inventory models for items deteriorating at a constant rate were discussed by Roy Chowdhury and Choudhuri (1983)..In a realistic product, life cycle demand is increasing with time during the growth phase. Chang and Dye (1999) developed an EOQ model with demand and partial backlogging. Naddar (1966) gives a detailed derivation of the total inventory cost for a constant demand rate lot size system, when the holding on hand in cost as qmt $\mathrm{n}$ where $\mathrm{q}$ denotes the amount of stock held and $\mathrm{t}$, the length of time, it is kept, $\mathrm{m}$ and $\mathrm{n}$ being positive integers. Chung (1998) studied the same model as Goyal (1985) and presented an alternative approach to find a theorem to determine the EOQ under condition of permissible delay in payments. In Goyal's (1985) model, it is assumed that no deterioration is allowed to occur and the capacity of the warehouse is unlimited. Chu et al. (1998) considered the same model as Aggarwal and Jaggi (1995) to show that the total cost per unit time is piece wise convex and develop a solution procedure to improve that described by Aggarwal and Jaggi (1995).

This study develops an inventory model for time-dependent demand when a delay in payment is permissible. The effect of inflation and delay in payments are discussed. Mathematical models are also derived under two different circumstances, i.e., Case 1: The credit period is less than or equal to the cycle time for settling the account and Case 2: The credit period is greater than the cycle time for settling the account. The expressions for an inventory system's total cost are derived for the above two cases, also. Moreover, an algorithm is developed to determine the optimal number of replenishment cycle time and order quantity. Finally, we provide numerical example and sensitivity for illustration the theoretical results. This paper is the extension of Hou and Lin (2009) in which the deterioration and demand rate both are constant.

In this Paper we have developed an inventory production model for a deteriorating product with under the condition of permissible delay in payments. Deteriorated products are provided with price discount for its deterioration rate. Shortage is not allowed in this model. Section 2 of this paper contains the information about the assumptions and notations. Then the model is followed by the Section 3. Numerical examples, tables, and final concluding remarks are discussed in the subsequent sections.

\section{ASSUMPTIONS AND NOTATION}

The following assumptions are used in the development of the model:

- Finite rate of the demand for the product which is known.

- Shortages are not allowed.

- An infinite planning horizon is assumed.

- The rate of production for each product is finite.

- Every unit of a product that is produced is available to meet the demand.

- The product starts deterioration when the production is terminated, and the price discount starts.

- The rate of production is independent of the production lot size.

- The time to deterioration of the product follows an exponential distribution.

- There is no replacement or repair for a deteriorated item.

- The production lot size is unknown which is constant.

- Inventory holding cost is charged for the un-decayed stock.

- The cost of deterioration unit is known and includes any disposal cost or salvage value.

- Customer is allowed credit period and the credit period is less than or equal to the production cycle time.

The notation employed in this Chapter is given below:

$p$ : rate of production of the particular product given in the number of units per unit time

$\mathrm{d}$ : actual demand of the product given in number of units per unit time.

$A$ : setup cost for the product.

$h$ : inventory carrying cost/unit/unit time for the product.

$k$ :production cost price per unit of the product

$r$ : price discount per unit of the product.

$M$ :permissible delay in payments (credit period).

$I_{E}$ :interest lost per unit time due to credit period.

$I_{E 1}$ : interest lost per unit time due to credit period where $M<T$ 
$I_{E 2}$ : interest lost per unit time due to credit period where $M>T$

$I_{P}$ :interest payable per unit time by the customer to the supplier for the time exceeding credit period.

$t_{1}$ : Production period.

$I_{1}\left(t_{1}\right)$ : Time varying inventory level for product in the cycle segment, $0 \leq t_{1} \leq T_{1}$.

$I(M)$ : Maximum inventory level of the product.

$\operatorname{TVC}(T)$ : Total cost/unit time.

\section{MATHEMATICAL MODEL}

The level of inventory starts with zero at the starting time of the production. The inventory accumulates with production to reach the maximum level which is $I_{1}\left(t_{1}\right)$ meeting the demand during the time $\left[0, t_{1}\right]$. During this period of time $\left[0, t_{1}\right]$ the inventory is built up at a rate $p-d$ and there is no deterioration. After the maximum inventory is reached, production is ended and the deterioration starts. Production will be resumed only after on hand inventories level reduces to zero at time $T$. Then the next production cycle run will begin. Since the time to deterioration of the product follows an exponential distribution is assumed, the inventory level of the system for the product at time $t$ over period $[0, T]$ can be the represented by the differential equations:

$\frac{d I(t)}{d t}+K(\beta, t) I(t)=P(t)-d ; \quad t \in[0, T]$

Where $P(t)= \begin{cases}P ; & t \in\left[0, t_{1}\right] \\ 0 ; & t \in\left[t_{1}, T\right]\end{cases}$

$K(\beta, t)=\left\{\begin{array}{lr}0 ; & t \in\left[0, t_{1}\right] \\ \frac{\beta(t-\lambda)^{\beta-1}}{(t-\lambda)^{\beta}} ; & t \in\left[t_{1}, T\right] ; t \neq \lambda\end{array}\right.$

Solving With the boundary condition $I(0)=0=I(T)$

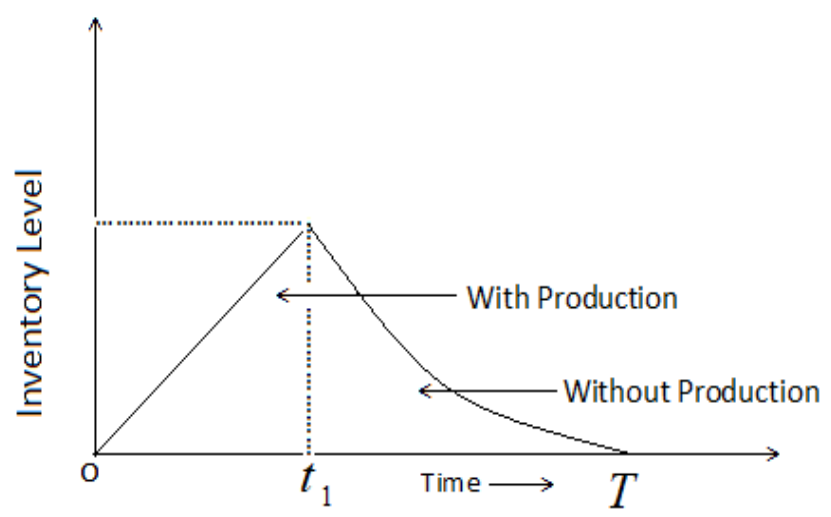

$\frac{d I(t)}{d t}=P-d ; \quad t \in\left[0, t_{1}\right]$

Solving the eqn (1) under condition $I(0)=0$ we get eqn (2)

$$
\begin{aligned}
& I(t)=(P-d) t ; t \in\left[0, t_{1}\right] \\
& \frac{d I(t)}{d t}+\frac{\beta(t-\lambda)^{\beta-1}}{(t-\lambda)^{\beta}} I(t)=-d ; \quad t \in\left[t_{1}, T\right]
\end{aligned}
$$

Solving the eqn (3) under condition $I(T)=0$ we get eqn (4)

$$
I(t)=\frac{-d}{\beta+1}\left[\frac{(t-\lambda)^{\beta+1}+(T-\lambda)^{\beta+1}}{(t-\lambda)^{\beta}}\right] ; t \in\left[t_{1}, T\right]
$$

By the continuity of $I(T)$ at $t=t_{1}$, Inventory level obtain its maximum.

$$
(P-d) t_{1}=\frac{-d}{\beta+1}\left[\frac{\left(t_{1}-\lambda\right)^{\beta+1}+(T-\lambda)^{\beta+1}}{\left(t_{1}-\lambda\right)^{\beta}}\right]
$$

By solving equation (5) for $t_{1}$ we can get the point of optimum inventory level of this model

(i) Ordering Cost $=A$

(ii) Production

(PC) $=c \int_{0}^{t_{1}} I(t) d t=c \int_{0}^{t_{1}}(P-d) t d t=c(P-d) \frac{t_{1}^{2}}{2}$

(iii)Holding Cost $(\mathrm{HC})=$

$$
\begin{aligned}
& h \int_{0}^{T} I(t) d t=h\left[\int_{0}^{t_{1}} I(t) d t+\int_{t_{1}}^{T} I(t) d t\right] \\
& =h\left[(P-d) \frac{t_{1}^{2}}{2}-\frac{d}{\beta+1}\left\{\frac{1}{2}\left(T^{2}-t_{1}^{2}\right)-\lambda\left(T-t_{1}\right)\right.\right. \\
& \left.\left.-\beta(T-\lambda)^{2}-(T-\lambda)^{\beta+1}\left(t_{1}-\lambda\right)^{1-\beta}\right\}\right]
\end{aligned}
$$

(iv) Deterioration Cost (DC) $=k \int_{t_{1}}^{T} I(t) d t$

$$
\begin{aligned}
= & k\left[(P-d) \frac{t_{1}^{2}}{2}-\frac{d}{\beta+1}\left\{\frac{1}{2}\left(T^{2}-t_{1}^{2}\right)-\lambda\left(T-t_{1}\right)\right.\right. \\
& \left.\left.-\beta(T-\lambda)^{2}-(T-\lambda)^{\beta+1}\left(t_{1}-\lambda\right)^{1-\beta}\right\}\right]
\end{aligned}
$$

(v)Price Discount (PD) $=k r \int_{0}^{T} I(t) d t$

$$
\begin{aligned}
= & k r\left[(P-d) \frac{t_{1}^{2}}{2}-\frac{d}{\beta+1}\left\{\frac{1}{2}\left(T^{2}-t_{1}^{2}\right)-\lambda\left(T-t_{1}\right)\right.\right. \\
& \left.\left.-\beta(T-\lambda)^{2}-(T-\lambda)^{\beta+1}\left(t_{1}-\lambda\right)^{1-\beta}\right\}\right]
\end{aligned}
$$


Total variable $\mathrm{Cost}=\mathrm{PC}+\mathrm{OC}+\mathrm{HC}+\mathrm{DC}+\mathrm{PD}$

$=A+\frac{1}{2}(P-d) t^{2}+\frac{1}{2(\beta+1)}\left[h(1+k+k r)(t-\lambda)^{-\beta}\right.$

$\left(P t^{2}(1+\beta)(t-\lambda)^{\beta}+d\left(-t^{2} \beta(t-\lambda)^{\beta}\right.\right.$

$\left.+T^{2}(2 \beta-1)(t-\lambda)^{\beta}\right)-2 T(2 \beta-1)(t-\lambda)^{\beta} \lambda$

$+2 \beta \lambda\left(T(T-\lambda)^{\beta}+(t-\lambda)^{\beta} \lambda-(T-\lambda)^{\beta} \lambda\right)$

$\left.-2 t\left(T B(T-\lambda)^{\beta}+(t-\lambda)^{\beta} \lambda-\beta(T-\lambda)^{\beta} \lambda\right)\right\rfloor$

We choose the parameter $\beta, k, r, h, A, c, \lambda$ in such way that

$\frac{\partial^{2} T V C}{\partial t^{2}}>0$ So that TVC will attains its minimum on $[0, T]$

Case 1: $M<T$

The loss of revenue to the supplier by way of interest is obtained as,

$I_{E_{1}}=\frac{k I_{E} d}{T} \int_{0}^{T}(T-t) d t=\frac{k I_{E} d T}{2}$

The interest payable by the customer to the supplier per unit time is,

$$
\begin{aligned}
& I_{P}=\frac{k I_{P}}{T} \int_{M}^{T} I(t) d t \\
& =\frac{k I_{P} d}{T(1+\beta)}\left[\frac{(M-\lambda)^{\beta+1}-(T-\lambda)^{\beta+1}}{(T-\lambda)^{\beta}}\right]
\end{aligned}
$$

Putting the above values in eqn (11),We get

$$
\begin{aligned}
& T V C_{1}(T)=P C+H C+D C+P D-I_{E 1}+I_{P} \\
& =c(P-d) \frac{t_{1}^{2}}{2}+h\left[(P-d) \frac{t_{1}^{2}}{2}-\frac{d}{\beta+1}\left\{\frac{1}{2}\left(T^{2}-t_{1}^{2}\right)\right.\right. \\
& \left.\left.-\lambda\left(T-t_{1}\right)-\beta(T-\lambda)^{2}-(T-\lambda)^{\beta+1}\left(t_{1}-\lambda\right)^{1-\beta}\right\}\right] \\
& +k\left[(P-d) \frac{t_{1}^{2}}{2}-\frac{d}{\beta+1}\left\{\frac{1}{2}\left(T^{2}-t_{1}^{2}\right)-\lambda\left(T-t_{1}\right)\right.\right. \\
& \left.\left.-\beta(T-\lambda)^{2}-(T-\lambda)^{\beta+1}\left(t_{1}-\lambda\right)^{1-\beta}\right\}\right] \\
& +k r\left[(P-d) \frac{t_{1}^{2}}{2}-\frac{d}{\beta+1}\left\{\frac{1}{2}\left(T^{2}-t_{1}^{2}\right)-\lambda\left(T-t_{1}\right)\right\}\right] \\
& \left.\left.-\beta(T-\lambda)^{2}-(T-\lambda)^{\beta+1}\left(t_{1}-\lambda\right)^{1-\beta}\right\}\right] \\
& +\frac{k I_{E} d T}{2}+\frac{k I_{P} d}{T(1+\beta)}\left[\frac{(M-\lambda)^{\beta+1}-(T-\lambda)^{\beta+1}}{(T-\lambda)^{\beta}}\right]
\end{aligned}
$$

Differentiating equation (6.3.14) with respect to $T$ and setting the result equal to zero we get, $\frac{\partial T V C_{1}(T)}{T}=h\left[\frac{-d}{\beta+1}(-\lambda-2 \beta(T-\lambda)\right.$

$$
\left.\left.-(\beta+1)(T-\lambda)^{\beta}\left(t_{1}-\lambda\right)^{1-\beta}\right)\right\rfloor
$$$$
+K(1+r)\left[\frac{-d}{\beta+1}(T-\lambda-2 \beta(T-\lambda)\right.
$$$$
\left.\left.-(\beta+1)(T-\lambda)^{\beta}\left(t_{1}-\lambda\right)^{1-\beta}\right)\right]
$$$$
+\frac{K I_{E} d}{2}+\frac{K I_{P} d}{T(1+\beta)}\left[(M-\lambda)^{1+\beta}(-\beta)(T-\lambda)^{-\beta-1}\right]=0(15)
$$

Again, differentiating equation (6.3.15) with respect to $T$ we get,

$$
\begin{aligned}
& \frac{\partial^{2} T V C_{1}(T)}{T^{2}}=h\left[\frac{-d}{\beta+1}\left(-2 \beta-(\beta+1)(T-\lambda)^{\beta-1}\left(t_{1}-\lambda\right)^{1-\beta}\right)\right] \\
& +K(1+r)\left[\frac{-d}{\beta+1}\left(1-2 \beta-(\beta+1) \beta(T-\lambda)^{\beta-1}\left(t_{1}-\lambda\right)^{1-\beta}\right)\right] \\
& +\frac{K I_{P} d}{T(1+\beta)}\left[\beta(\beta+1)(M-\lambda)^{1+\beta}(-\beta)(T-\lambda)^{-\beta-2}\right]=0
\end{aligned}
$$

We choose the parameter $\alpha, \beta$ in such a way that $\frac{\partial^{2} T V C_{1}(T)}{T^{2}}>0$, so that $T V C_{1}$ will be minimum.

\section{Case-2: $M>T$}

In this study the customer need not pay interest i.e.no need of $I_{P}$.

$$
\begin{aligned}
& I_{E 2}=\frac{p I_{E} d}{T}\left(\int_{0}^{T}(T-t) d t+(M-T) \int_{0}^{T} d t\right) \\
& =p I_{E} d\left(M-\frac{T}{2}\right)
\end{aligned}
$$

Now, using the above values we get,

$$
\begin{aligned}
& T V C_{2}(T)=P C+H C+D C+P D-I_{E 2} \\
& =c(P-d) \frac{t_{1}^{2}}{2}+h\left[(P-d) \frac{t_{1}^{2}}{2}-\frac{d}{\beta+1}\left\{\frac{1}{2}\left(T^{2}-t_{1}^{2}\right)-\lambda\left(T-t_{1}\right)\right.\right. \\
& \left.\left.-\beta(T-\lambda)^{2}-(T-\lambda)^{\beta+1}\left(t_{1}-\lambda\right)^{1-\beta}\right\}\right] \\
& +k\left[(P-d) \frac{t_{1}^{2}}{2}-\frac{d}{\beta+1}\left\{\frac{1}{2}\left(T^{2}-t_{1}^{2}\right)-\lambda\left(T-t_{1}\right)\right.\right.
\end{aligned}
$$


“An Inventory Production Model for Deteriorating Items Allowing Price Discount with Permissible Delay in Payments"

$\left.\left.-\beta(T-\lambda)^{2}-(T-\lambda)^{\beta+1}\left(t_{1}-\lambda\right)^{1-\beta}\right\}\right]$

$+k r\left[(P-d) \frac{t_{1}^{2}}{2}-\frac{d}{\beta+1}\left\{\frac{1}{2}\left(T^{2}-t_{1}^{2}\right)-\lambda\left(T-t_{1}\right)\right.\right.$

$\left.\left.-\beta(T-\lambda)^{2}-(T-\lambda)^{\beta+1}\left(t_{1}-\lambda\right)^{1-\beta}\right\}\right]$

$-p I_{E} d\left(M-\frac{T}{2}\right)$

Differentiating equation (6.3.18) with respect to $T$ and setting the result equal to zero we get,

$\frac{\partial T V C_{2}(T)}{T}=(h+K+K r)\left[\frac{-d}{\beta+1}(T-\lambda-2 \beta(T-\lambda)\right.$

$\left.\left.-(\beta+1)(T-\lambda)^{\beta}\left(t_{1}-\lambda\right)^{1-\beta}\right)\right]+\frac{P I_{E} d}{2}=0$

Again, differentiating equation (6.3.19) with respect to $T$ we get,

$$
\begin{aligned}
& \frac{\partial^{2} T V C_{2}(T)}{T^{2}}=(h+K+K r) \\
& {\left[\frac{-d}{\beta+1}\left(1-2 \beta-(\beta+1) \beta(T-\lambda)^{\beta-1}\left(t_{1}-\lambda\right)^{1-\beta}\right)\right]>0}
\end{aligned}
$$

We choose the parameter $\alpha, \beta$ in such a way that $\frac{\partial^{2} T V C_{2}(T)}{T^{2}}>0$, so that $T V C_{2}$ will be minimum.

\section{NUMERICAL EXAMPLES}

Let $A=100, P=1000, d=20, k=0.04, h=4, \beta=2$, $r=8, c=20, \lambda=1$ in their units and using equation (11) the optimal total variable cost TVC are find to be TVC $=2$ and maximum inventory level $I\left(t_{1}\right)=373410$ at $t_{1}=4.65, T=10.02$.

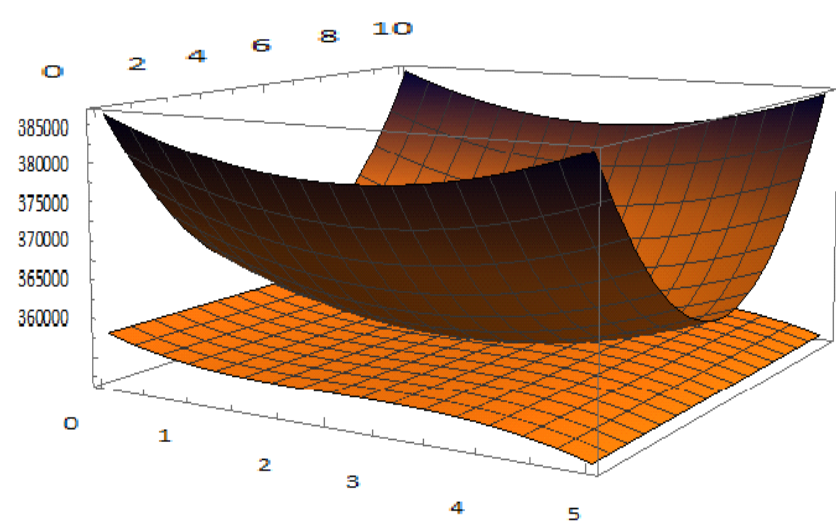

Fig no (2) total inventory cost

\begin{tabular}{|c|c|c|c|c|c|}
\hline $\begin{array}{l}\text { Paramete } \\
\text { r }\end{array}$ & $\begin{array}{l}\% \\
\text { Chan } \\
\text { ges of } \\
\text { Para } \\
\text { meter }\end{array}$ & $\begin{array}{l}\text { Change } \\
d \text { value } \\
\text { of } \\
\text { Parame } \\
\text { ter }\end{array}$ & $t_{1}$ & TVC & $\begin{array}{l}\text { \% } \\
\text { Change } \\
\mathrm{s} \quad \text { of } \\
\mathrm{TVC}\end{array}$ \\
\hline \multirow{5}{*}{$A=100$} & -50 & 50 & 4.83 & 365942 & $+1.01 \%$ \\
\hline & -25 & 75 & 4.72 & 371356 & $+0.55 \%$ \\
\hline & 0 & 100 & 4.65 & 373410 & 0 \\
\hline & +25 & 125 & 4.59 & 375501 & $-0.56 \%$ \\
\hline & +50 & 150 & 4.47 & 377890 & $-1.12 \%$ \\
\hline \multirow{5}{*}{$P=1000$} & -50 & 500 & 4.53 & 362954 & $-2.78 \%$ \\
\hline & -25 & 750 & 4.57 & 366651 & $-1.18 \%$ \\
\hline & 0 & 1000 & 4.65 & 373410 & $0 \%$ \\
\hline & +25 & 1250 & 4.71 & 379737 & $+1.74 \%$ \\
\hline & +50 & 1500 & 4.79 & 384612 & $+2.81 \%$ \\
\hline \multirow{5}{*}{$d=20$} & -50 & 10 & 4.61 & 339803 & $-0.92 \%$ \\
\hline & -25 & 15 & 4.63 & 355859 & $-0.47 \%$ \\
\hline & 0 & 20 & 4.65 & 373410 & $0 \%$ \\
\hline & +25 & 25 & 4.67 & 392080 & $+0.51 \%$ \\
\hline & +50 & 30 & 4.70 & 411871 & $+1.03 \%$ \\
\hline \multirow{5}{*}{$k=0.04$} & -50 & 0.2 & 5.01 & 380878 & $+0.20 \%$ \\
\hline & -25 & 0.3 & 4.83 & 377142 & $+0.10 \%$ \\
\hline & 0 & 0.4 & 4.65 & 373410 & $0 \%$ \\
\hline & +25 & 0.5 & 4.47 & 369676 & $-0.10 \%$ \\
\hline & +50 & 0.6 & 4.31 & 365941 & $-0.20 \%$ \\
\hline \multirow{5}{*}{$h=4$} & -50 & 2 & 4.69 & 38087 & $+0.3 \%$ \\
\hline & -25 & 3 & 4.67 & 377944 & $+0.1 \%$ \\
\hline & 0 & 4 & 4.65 & 373410 & $0 \%$ \\
\hline & +25 & 5 & 4.63 & 369675 & $-0.1 \%$ \\
\hline & +50 & 6 & 4.61 & 362207 & $-0.3 \%$ \\
\hline \multirow{5}{*}{$\beta=2$} & -50 & 1.50 & 5.23 & 358473 & $-4.15 \%$ \\
\hline & -25 & 1.75 & 4.92 & 344623 & $-2.08 \%$ \\
\hline & 0 & 2.00 & 4.65 & 373410 & $0 \%$ \\
\hline & +25 & 2.25 & 4.31 & 387423 & $+2.10 \%$ \\
\hline & +50 & 2.50 & 4.07 & 401259 & $+4.25 \%$ \\
\hline \multirow{5}{*}{$r=8$} & -50 & 4 & 3.07 & 250185 & $\begin{array}{l}- \\
33.98 \%\end{array}$ \\
\hline & -25 & 6 & 3.87 & 342867 & $\begin{array}{l}- \\
17.01 \%\end{array}$ \\
\hline & 0 & 8 & 4.65 & 373410 & $0 \%$ \\
\hline & +25 & 10 & 5.39 & 440624 & $\begin{array}{l}+18.05 \\
\%\end{array}$ \\
\hline & +50 & 12 & 6.12 & 504104 & $\begin{array}{l}+35.02 \\
\%\end{array}$ \\
\hline \multirow{3}{*}{$c=20$} & -50 & 10 & 2.31 & 186705 & $\begin{array}{l}- \\
50.01 \%\end{array}$ \\
\hline & -25 & 15 & 3.92 & 280057 & $\begin{array}{l}- \\
25.03 \%\end{array}$ \\
\hline & 0 & 20 & 4.65 & 373410 & $0 \%$ \\
\hline
\end{tabular}

\section{Table-1}




\begin{tabular}{|l|l|l|l|l|l|}
\hline \multirow{1}{*}{$\lambda=1$} & +25 & 25 & 6.21 & 466762 & $\begin{array}{l}+26.03 \\
\%\end{array}$ \\
\cline { 2 - 6 } & +50 & 30 & 7.82 & 560115 & $\begin{array}{l}+52.07 \\
\%\end{array}$ \\
\hline \multirow{4}{*}{$\lambda$} & -50 & 0.50 & 4.65 & 373410 & $0 \%$ \\
\cline { 2 - 6 } & -25 & 0.75 & 4.65 & 373410 & $0 \%$ \\
\cline { 2 - 6 } & 0 & 1.00 & 4.65 & 373410 & $0 \%$ \\
\cline { 2 - 6 } & +25 & 1.25 & 4.65 & 373410 & $0 \%$ \\
\cline { 2 - 6 } & +50 & 1.50 & 4.65 & 373410 & $0 \%$ \\
\hline
\end{tabular}

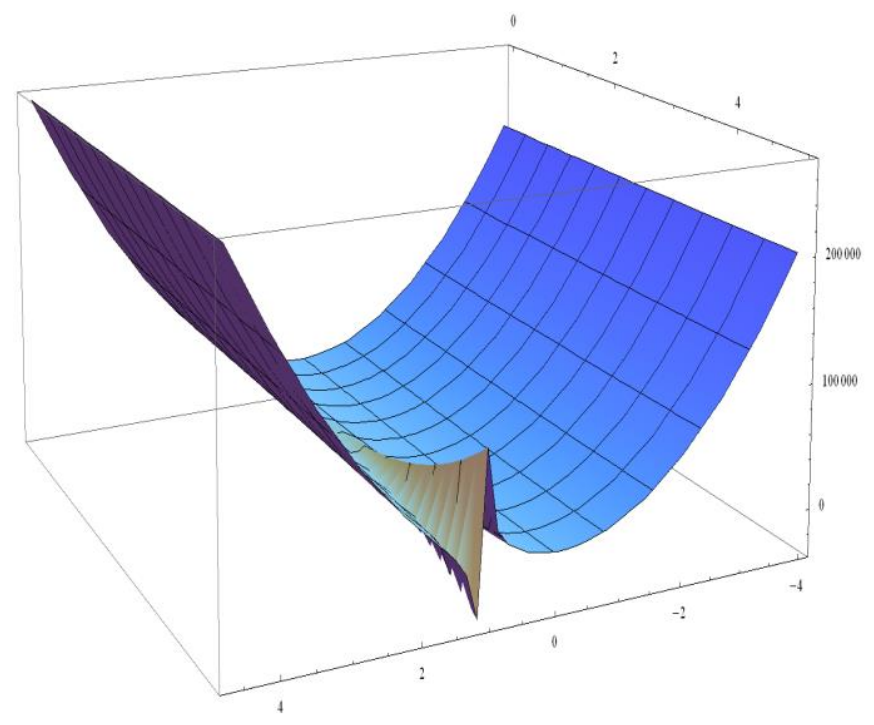

Fig no (3) Graphical representation of TVC

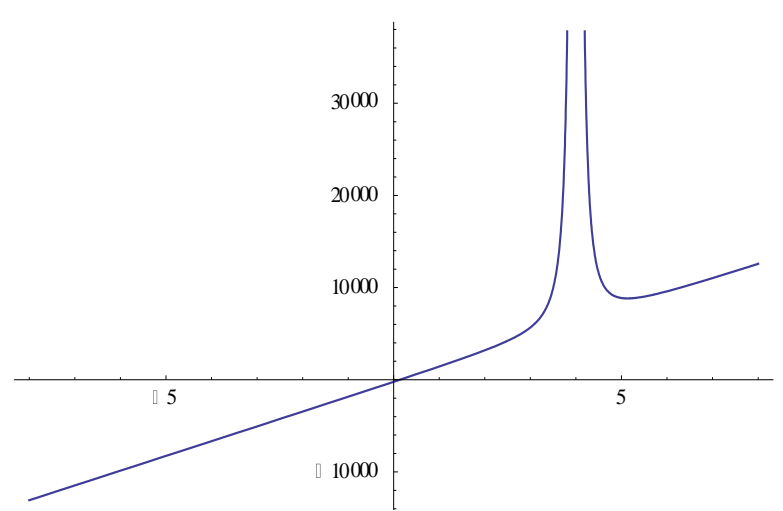

Fig no (4) Graphical representation of TVC

\section{SENSITIVITY ANALYSIS}

The value of total cost in this inventory model effected by the changing value of the parameters. Here, we have examine the change of value of the parameters in a quarterly order like $+50 \%,+25 \%, 0 \%,-25 \%,-50 \%$ and we observed that the change in value in TVC followed the respective direction with some parameters like c,r, $\beta, \mathrm{d}$ and opposite direction with some parameters like $\mathrm{A}, \mathrm{k}, \mathrm{h}$.The value of TVC remain unchanged by changing value of the parameter $\lambda$.

\section{CONCLUSION}

The present paper deals with an inventory production policy for a ramp type deteriorating item over a finite planning horizon with constant demand, finite production rate and shortages are not allowed. The optimal number of production cycles that minimizes the average system cost is determined. The model permits inventory shortage in each cycle, which is completely backlogged within the cycle itself. Fig no.1 represents the inventory level of the proposed model. Every cycle starts with zero stock and production. As production continues, the inventory begins to accumulate after meeting current demands. The excess inventory accumulated during the production period is used to account for demand and deterioration in the no-production period. Fig no 2, 3 and 4 are representing the TVC of the proposed model. Due to several practical reasons, production may not restart as soon as the accumulated inventory is fully exhausted. Such practical reasons may be like a delay in machine maintenance, for example, lack of raw materials, shortage of labour, breakdown of the power unit, lack of capital, etc.

\section{REFERENCES}

1. Aggarwal, S.P. and Jaggi, C.K. 1995. Ordering policies of deteriorating items under permissible delay in payments, Journal of Operational Research Society, Vol 46, pp.458-462.

2. Agrawal,R. ,Rajput, D. and Varshney, N.K. 2009. Integrated inventory system with the effect of inflation and credit period. International Journal of Applied Engineering Research. Vol 4, No.11, pp. 2334-2348.

3. Bishi, B. and Sahu,S,K. 2018. Deteriorating inventory model with linear, exponential demand with shortage, International Journal of Research in Humanities, Arts and Literature, 7,171-182.

4. Bishi, B. Behera, J. and Sahu S.K.. 2018. TwoWarehouse Inventory Model for Non-Instantaneous Deteriorating Items with Exponential Demand Rate, International Journal of Applied Engineering Research, 14, 495-515.

5. Chang, H.J. and Dye, C.Y.1999. An EOQ model for deteriorating items with time varying demand and partial backlogging, Journal of the Operational Research Society. Vol 50, No.11, pp.1176-1182.

6. Chu, P., Chung, K.J. and Lan, S.P. 1998. Economic order quantity of deteriorating items under permissible delay in payments, Computers and Operations Research. Vol 25, pp.817-824. 
7. Chung, K.H. 1998. A theorem on the determination of economic order quantity under conditions of permissible delay in payments, Computers and Operations Research. Vol 25, pp. 49-52.

8. Dave, U. 1985. On economic order quantity under conditions of permissible delay in payments by Goyal, Journal of Operational Research Society, Vol 36, pp.1069.

9. Davis, R.A. and Gaither. 1985. Optimal ordering policies under condition of extended payment privileges, Management Science, Vol 31, pp.499509.

10. Ghare, P.M. and Shrader, G.F. 1963. A model for exponentially decaying inventory. J. Ind. Eng., Vol 14, pp.238-243.

11. Goyal, S.K. 1985. Economic order quantity under conditions of permissible delay in payments, Journal of the Operational Research Society, Vol 36, pp.335-338.

12. Hou, K.L. and Lin, L. C. 2009. A cash flow oriented EOQ model with deteriorating items under permissible delay in payments. Journal of Applied Sciences. Vol 9, No.9, pp.1791-1794.

13. Huang,Y.F. 2007. Economic order quantity under conditionally permissible delay in payments. European Journal of Operational Research. Vol 176, pp. 911-924.

14. Jaggi,C.K., Goyal,S.K. and Goel,S.K. 2008. Retailer's optimal replenishment decisions with credit-linked demand under permissible delay in payments. European Journal of Operational Research. Vol 190, pp. 130-135.

15. Jaggi,C.K.Aggarwal,K.K. and Goel,S.K. 2007. Retailer's optimal ordering policy under two stage trade credit financing. Advanced Modeling and Optimization. Vol 9, No.1, pp. 67-80.

16. Jamal, A.A.M., Sarker, B.R. and Wang, S. 1997. An ordering policy for deteriorating items wills allowable shortage and permissible delay in payments. Journal of Operational Research Society, Vol 48, pp.826-833.

17. Mahata, G.C. and Mahata, P. 2009. Optimal retailer's ordering policies in the EOQ model for deteriorating items under trade credit financing in supply chain. International Journal of Mathematical, Physical and Engineering Sciences. Vol 3 No.1, pp. 1-7.

18. Naddor, E. 1966. Inventory Systems. Wiley, New York. Ouyang, L.Y., Wu, K.S. and Yang, C.T. 2006. A study on an inventory model for noninstantaneous deteriorating items with permissible delay in payments, Comput. Ind. Eng., Vol 51, pp. 637-651.
19. Roychowdhury, M. and Chaudhuri, K.S. 1983. An order level inventory mode for deteriorating items with finite rate of replenishment, Opsearch. Vol 20, pp.99-106.

20. Sarker, B.R., Jamal, A.A.M. and Wang, S. 2000. Supply chain model for perishable product under inflation and permissible delay in payments. Comput. Operat. Res.,Vol 27, pp.59-75.

21. Tripathi,R.P. and Misra, S.S. 2010. Credit financing in economic ordering policies of non- deteriorating items with time - dependent demand rate. International Review of Business and Finance. Vol 2, No. 1, pp. 47-55. 